\title{
A nacionalização da electricidade em Portugal
}

Dossier Eletromemoria: PAISAGem E HistóRIA

\section{Nuno Luís Madureira}

ISCTE-IUL. Professor Associado, Departamento História. Lisboa [Lisboa] Portugal.

$<$ nuno.madureira@iscte.pt>.

\section{Resumo}

Este artigo mostra que a nacionalização da electricidade em Portugal ocorrida na transição para o regime democrático não representou uma rotura em relação ao regime ditatorial do Estado Novo. Três ideias, a de empresa única (1966-1974), de nacionalização técnica (1974-1975) e de nacionalização política (1975-1976) prolongaram na prática a estratégia de fusões de empresas de serviço público e de concentração de activos Municipais levadas a cabo desde os anos 1960.

\section{Palavras-chave}

Electricidade, nacionalização, energia, política econômica, empresas públicas, revolução.

\section{The nationalization of electricity in Portugal}

\section{Abstract}

This article shows that the nationalization of electricity in Portugal took place in the democratic system for the transition did not represent a break with respect to the Estado Novo dictatorship. Three ideas, the only company (1966-1974), technical nationalization (1974-1975) and policy nationalization (1975-1976) pursued in practice the similar strategy of company mergers and concentration of Municipal assets carried out since the 1960s.

\section{Keywords}

Electricity, state owned enterprises, energy, economic policy, public sector, revolution. 


\section{Introdução}

A ideia de que as nacionalizações nascem de consensos político-sociais pode parecer estranha. No entanto as nacionalizações francesa e inglesa de 1946-1949 e a nacionalização italiana da electricidade, de 1962, encaixam-se neste perfil. Politicamente foram apoiadas por socialistas e democratas-cristãos mas também por conservadores, trabalhistas e comunistas. Além disso, receberam o apoio de sectores sociais descontentes com o serviço prestado pelas empresas durante a guerra (Reino Unido); de gente que desconfiava do excesso de colaboracionismo de algumas empresas (França) e de gente que defendia que o serviço público era o melhor meio para canalizar investimento para as terras mais pobres do sul (Itália).

Apesar das grandes diferenças de opinião, o ponto da convergência das nacionalizações Europeias acima citadas está na ideia de que um serviço público, contemplando os sectores básicos de energia, transportes e telecomunicações, tem finalidades comerciais mas também finalidades redistributivas: deve em primeiro lugar assegurar um serviço universal de cobertura geográfica de todo o território; deve, em segundo lugar assegurar a igualdade de tarifas (todos os cidadãos pagam o mesmo por serviço idêntico, independentemente do custo do serviço). Denominado "postalisation" por referência ao sistema de selo de carta universal utilizado pelos Postos de Correios Britânicos ("Post Office"), este princípio traduziu a orientação de colocar os consumidores de grandes cidades a pagar pela melhoria das condições de vida da população dispersa dos campos.

No caso concreto da nacionalização da electricidade, esperava-se que os ganhos de eficiência com a integração das redes superassem os custos redistributivos. Dado o momento tecnológico de pré integração de redes privadas, esses ganhos seriam gerados pela normalização dos equipamentos e das correntes de voltagem, a estandardização da construção de novas centrais, a integração de centrais com diferentes picos horários, a coordenação operada a partir da rede de transporte, as economias de escala e o aproveitamento das economias de rede. Em França estas ideias serviram para forjar a legitimidade da integração dos seis grupos regionais privados numa empresa pública única. Na verdade, a empresa Electricidade de França - EDF - foi rapidamente capaz de consolidar um sistema tarifário universal para o cliente residencial e um sistema de cobrança eficiente baseado na tarifação ao custo marginal para os clientes de alta tensão.

Por meados da década de 1970 há uma segunda vaga de nacionalizações com epicentro em Portugal (1975) e na Grécia (1975-1981). Além da electricidade, a expropriação abarca um conjunto de grandes empresas nos sectores estratégicos da banca, refinação petrolífera, seguros e outros. No entanto, o curso dos acontecimentos é profundamente diferente: o processo é desencadeado por uma radicalização revolucionária anti-capitalista em Portugal enquanto na Grécia é um governo de centro direita que procura desferir um golpe nos grupos empresariais identificados com o antigo regime. Os objectivos gerais reiteram contudo os princípios da igualdade tarifária, serviço universal e correcção de assimetrias regionais.

Este artigo traça a história da nacionalização da electricidade em Portugal. Uma primeira parte analisa a proposta de expropriação dos privados e do sector municipal equacionada no tempo da ditadura. De seguida são examinadas as propostas de nacionalização que entram na agenda política dos governos provisórios da primeira fase de transição para a democracia após a revolução de 25 de Abril de 1974. Finalmente, explicam-se os acontecimentos que despoletaram a nacionalização, no período "quente" de 1975, já sob a bandeira da transição para socialismo e do "processo revolucionário". Devido ao facto de o sector público ser à partida dominante, é altamente provável que a nacionalização tivesse acontecido mesmo sem a conjuntura de fim da ditadura e da fase revolucionária. Dados os avanços na integração da rede pública é na verdade de crer que as empresas residuais do sistema eléctrico viessem a ser expropriadas. Por estas razões, não obstante o carácter revolucionário da nacionalização portuguesa, ela acaba por ser relativamente consensual, pois é o elo comum na política económica de diferentes regimes políticos.

\section{As primeiras propostas de nacionalização}

No período da ditadura (1932-1974), o investimento público na construção de barragens constituiu

MADUREIRA, N.L.. A nacionalização da electricidade em Portugal. Labor \& Engenho, Campinas [SP] Brasil, 
uma trave mestra da estratégia desenvolvimentista portuguesa. Desde a publicação da Lei de Electrificação, em 1944, que as empresas particulares começam a ver a sua expansão condicionada por princípios de serviço público. Graças à capacidade de adaptação às novas realidades, conseguem contudo sobreviver. Com a chegada ao poder de Marcelo Caetano, em Setembro de 1968, abre-se porém um segundo ciclo de ameaças proveniente da expansão e concentração do sector público. Neste ciclo, os privados do sector eléctrico e os municípios locais correm o risco de perder quotas de mercado e ficarem definitivamente entalados entre duas movimentações que se detectam no governo:

- A primeira é impulsionada por Gonçalves Rapazote, Ministro do Interior, e preconiza a fusão da pequena distribuição de electricidade, mediante o licenciamento de Federações de Municípios com poderes alargados. A nova arquitectura para o sector prevê ganhos em economias de escala, integrando os equipamentos e a administração de serviços municipais dispersos, de modo a criar grandes entidades regionais com capacidade financeira e organizativa. A estas entidades competiria distribuir a electricidade aos consumidores finais. Ora o reavivar do protagonismo do sector municipal tem consequências sobre as estratégias dos distribuidores privados: a curto prazo os privados perdem oportunidades para estabelecer contratos com municípios isolados; a médio prazo correm o risco de verem as suas áreas de concessão trespassadas para novas federações regionais. Cooptado para o governo em nome da linha ideológica e militante do Estado Novo, o ministro Gonçalves Rapazote pretende devolver protagonismo às bases "naturais" de apoio ao governo, ressuscitando o modelo de economia corporativa que, embora previsto na lei, apenas estava implantado numa única região (a Federação dos Municípios de Évora, Arraiolos e Redondo, criada em 1960). Durante o "Marcelismo" (1968-1974), novas Federações de Municípios vão obter reconhecimento legal nas regiões de Leiria, Ribatejo, Setúbal, Faro, Viseu, Trás os Montes e Alto Douro, e Castelo Branco.

- A segunda movimentação, de natureza predominantemente empresarial, conta com o apoio dos Ministros das Finanças e da Economia, Augusto Dias Rosa e Artur Cota Dias, e traduz-se na fusão das empresas concessionárias da Rede Primária, concentrando as produtoras de serviço público hidroeléctrico, térmico e as linhas de transporte numa única entidade. À empresa resultante - Companhia Portuguesa de Electricidade CPE é atribuída a concessão por prazo indeterminado da produção e do transporte de energia eléctrica, o que equivale, na prática, a uma nacionalização preventiva do sector (Decreto lei 49211 de 27 de Agosto de 1969).

Convém esclarecer que esta possibilidade é ventilada desde há uns anos nos círculos governamentais, através do Grupo de Trabalho encarregue de estudar a reestruturação do sector eléctrico (despacho do Secretário de Estado da Indústria de 23/11/1966). Esse Grupo de Trabalho alarga aliás o diagnóstico sugerindo normas para a concentração do sector público numa única entidade e antevendo uma nacionalização "gradualmente justaposta às estruturas privadas existentes" ${ }^{11}$ no caso de o próprio planeamento da rede de transporte a muito alta tensão, continuar a ser feito com relativa independência em relação ao planeamento dos centros produtores privados - "o que é evidentemente anómalo, já que as linhas representam afinal o prolongamento natural das centrais até aos centros de consumo além de assegurarem a interligação entre os nós da rede assim formada"2. Por outras palavras, o tema da nacionalização entra no catálogo de opções políticas do Estado Novo, sob o argumento da racionalização técnico-económica e do planeamento dos investimentos na rede eléctrica.

Compreende-se assim o tipo de pressão que é exercida sobre as empresas nos anos do Marcelismo. Os privados são ameaçados de perderem a distribuição em baixa tensão para as Federações de

\footnotetext{
${ }^{1}$ CD/ME. EDP: Relações Institucionais. Relatório do Grupo de trabalho criado pela Comissão nomeada por despacho do Secretário de Estado da Indústria de 23/11/1966 para estudar a reestruturação das empresas concessionárias da rede primária. 23 de Novembro de 1966. Este grupo é constituído por José Maria Galvão Teles (Presidente) Jorge de Aguiar (Secretário); António Pires de Carvalho; Mário Gomes; Teófilo de Carvalho; Walter Rosa.
}

${ }^{2}$ Ibidem, Ibidem. 
Municípios, e, por outro lado, a necessidade de reduzirem o seu peso na produção e no transporte de energia, devido à primazia concedida à empresa única concessionária da rede primária de serviço público - a Companhia Portuguesa de Electricidade.

O Quadro 1 faz um ponto da situação das mudanças em curso, por altura da revolução do 25 de Abril de 1974. Sobressai primeiro que tudo o facto de o sector privado estar acantonado no mercado de distribuição de electricidade, sobretudo em alta tensão. A linha relativa às grandes empresas privadas mostra a este respeito que o mercado "disponível" para nacionalização representa menos de $9 \%$ da produção eléctrica e $65 \%$ da distribuição. 0 retrato do sector é assim de uma verdadeira economia mista com uma empresa única de serviço público a monopolizar a geração de energia e uma dispersão considerável no sector da distribuição. Verifica-se ainda que, à medida que passamos para a área das "vendas a retalho" da baixa tensão, aumenta a quota de mercado das entidades ligadas ao poder local. 0 projecto do Ministro Gonçalves Rapazote fica, apesar de tudo, a meio caminho: em três ou quatro anos, as Federações de Municípios conseguem chegar a quase 11\% da distribuição em baixa tensão, números que representam um progresso notório face ao início recente das actividades, mas que não beliscam a posição de outras entidades. 0 desígnio de renascimento de um corporativismo municipalista acaba por ser claramente surpreendido pela revolução de 1974.

Quadro 1. Quotas dos vários sectores económicos nos mercados de electricidade em 1974.

\begin{tabular}{|c|c|c|c|}
\hline \multirow[t]{2}{*}{ Entidade } & \multirow{2}{*}{$\begin{array}{l}\text { Quota de mercado } \\
\text { na produção de } \\
\text { electricidade }\end{array}$} & \multicolumn{2}{|c|}{$\begin{array}{l}\text { Quota de mercado na distribuição } \\
\text { de electricidade }\end{array}$} \\
\hline & & $\begin{array}{l}\text { Em alta e em } \\
\text { baixa tensão }\end{array}$ & em baixa tensão \\
\hline $\begin{array}{l}\text { Companhia Portuguesa de } \\
\text { Electricidade - CPE }\end{array}$ & $90,9 \%$ & $11,4 \%$ & $0,7 \%$ \\
\hline Empresas privadas* & $8,8 \%$ & $65,5 \%$ & $40,1 \%$ \\
\hline Federações de Municípios & $0,1 \%$ & $4,2 \%$ & $10,7 \%$ \\
\hline Outros** & $0,2 \%$ & $18,9 \%$ & $49,5 \%$ \\
\hline Total & $100 \%$ & $100 \%$ & $100 \%$ \\
\hline
\end{tabular}

* Empresas Privadas abrange as grandes empresas de produção e distribuição nacionalizadas pelo decreto lei no 205 G/75. de 16 de Abril de 1975.

** Outros abrange serviços municipalizados, câmaras municipais, cooperativas e pequenas empresas privadas não nacionalizadas pelo decreto lei no 205-G/75. de 16 de Abril de 1975.

Fontes: Cálculos baseados em DGSE — Estatística das instalações eléctricas 1974. Lisboa: DGSE, 1975; CD/ME. EDP: Tarifas, Proposta para um ajustamento das tarifas de venda eléctrica no país, Março de 1976; CD/ME. EDP: Integração da Distribuição, Relatório da Comissão de Estudo para a Integração da pequena distribuição, 27 de Julho de 1976.

Subsiste apesar de tudo um tabu nas camadas dirigentes do Estado Novo em relação à hipótese de nacionalização, pelo que isso pode significar de violência sobre os direitos de propriedade e de alteração da ordem estabelecida. Ora, com o 25 de Abril de 1974, o tabu desaparece. Na ordem do dia fica o tema da "reestruturação do sector" cujo desenvolvimento leva à "eventual negociação da transferência forçadas das concessões" ${ }^{3}$. Racionalizar e expropriar tornam-se faces de uma mesma moeda pois, graças à revolução, o tempo de mudanças gradualistas do Marcelismo pode agora ser acelerado.

\section{As segundas propostas de nacionalização}

Nos meses que se seguem à revolução de 25 de Abril de 1974, os técnicos sugerem aos Ministros que a melhor solução para modernizar o sector é a integração vertical, isto é colocar a produção, o transporte e toda a distribuição de electricidade sob a tutela de uma única empresa. Claro que a ideia tem implícita a necessidade de expropriar os privados e as entidades do poder local.

\footnotetext{
${ }^{3}$ CD/ME. EDP: Tarifas. Relatório do Grupo de trabalho criado por despacho do Ministro da Administração Interna e do Secretário de Estado da Indústria e Energia de 21 de Junho de 1974. Agosto de 1974, p. 58.
} 
Pretende-se avançar um passo mais no processo de fusões que têm início com Marcelo Caetano, em 1969, e concentrar todo o sector. Os ganhos de eficiência e de produtividade que justificam esta opção são sobretudos ganhos de coordenação das economias de escala e de rede. A saber:

- Normalizar o equipamento e concentrar o planeamento das encomendas. Estandardizar para potenciar economias de escala é visto como forma de obviar ao "aparecimento de pequenas empreitadas, possivelmente de volume total inferior, devido à escassez de recursos financeiros e todas diferentes umas das outras, impossibilitando a organização de empreiteiros e fornecedores, e obrigando ao recurso sistemático a material estrangeiro, por ser impossível conhecer os ritmos e as sequências que cada pequena empresa adopta"4.

- Planear a rede de transporte de forma integrada, pondo fim à relativa independência de planeamento quer dos centros produtores dispersos quer linhas que asseguram a interligação entre os nós da rede.

- Melhorar a qualidade de serviço e generalizar a cobertura da distribuição de electricidade a todo o país, centralizando recursos técnicos e financeiros, sobretudo para actividades com baixo retorno de investimentos como é o caso da electrificação rural.

- Uniformizar o sistema tarifário criando uma tarifa única no território de Portugal Continental. Na conjuntura concreta de 1974 o "sucessivo aumento do preço dos factores" corre o risco de levar a "aumentos dos preços da electricidade, que, repercutindo-se desigualmente, tornariam caóticas as já desordenadas tarifas de energia eléctrica existentes no país"5.

Em Agosto de 1974, as dúvidas dissipam-se. No horizonte próximo está já a possibilidade de nacionalização e o grupo de trabalho que aconselha o Ministro e o Secretário de Estado do IIo Governo Provisório "recomenda que o governo promova a constituição de uma empresa única, mediante a fusão das entidades do sector da energia eléctrica" ${ }^{6}$. Todos os consultores deste grupo vão exercer cargos de maior destaque nos próximos anos. Entre eles, está Rui Machete, um dirigente do Partido Popular Democrático - PPD - , de centro direita. Há pois um consenso transversal ao leque político-partidário em torno da eventual nacionalização técnica: a gestão pública de sectores chave da economia consta do programa dos principais partidos políticos que participam na área governativa (PS, PCP, PPD) e apenas o Centro Democrático Social — CDS - , claramente situado à direita, defende uma economia de matriz liberal sem reforço do peso do Estado ${ }^{7}$.

Entretanto, o processo político português inicia uma guinada para a esquerda no verão de 1974. Este é o momento de isolamento político do Presidente da República, António de Spínola, com o fracasso da tentativa de reforço dos poderes presidenciais; da escalada do movimento de ocupação de terras, casas e empresas, do reforço da influência do Movimento das Forças Armadas nas pastas dos Governos Provisórios. No entanto, apesar desta deriva política, a proposta de criação de uma empresa única do Estado significa um alinhamento com a tradição europeia de serviço público no sector da energia (França, Inglaterra, Itália) e não uma aposta na mudança de regime económico. Por enquanto é ainda a modernização social e a "democracia socialista" que estão em cima da mesa.

Numa apreciação mais rigorosa, convém esclarecer que a expropriação de direitos de propriedade é considerada um expediente de última instância. Em princípio, espera-se que as empresas particulares aceitem participar voluntariamente no processo de fusão e que os serviços explorados por autarquias locais e federações de municípios sigam o mesmo exemplo, recebendo em troca direitos de participação

\footnotetext{
${ }^{4}$ CD/ME. EDP: Relações Institucionais. A reestruturação da electricidade causas e objectivos. Documento de trabalho dactilografado de António Leite Garcia. Julho de 1974.

${ }^{5}$ Ibidem, Ibidem.

${ }^{6}$ CD/ME. EDP: Tarifas. Relatório do Grupo de trabalho criado por despacho do Ministro da Administração Interna e do Secretário de Estado da Indústria e Energia de 21 de Junho de 1974, Agosto de 1974.
}

${ }^{7}$ VIEGAS, José Manuel. Nacionalizações e Privatizações. Celta: Lisboa, 1996, p. 142-166. 
no capital da nova Empresa. "Admite-se no entanto a possibilidade de algumas empresas não desejarem participar no processo de fusão por pretenderem manter a sua existência jurídica ou por quaisquer razões". E "para garantir a consecução dos objectivos pretendidos com a criação da empresa única, prevê-se a possibilidade de transferência forçada, mediante indemnização das concessões, instalações e serviços explorados pelas sociedades que se recusarem à fusão"8.

Menos de um mês depois de receber esta proposta, o Governo está já de saída. Nos conturbados tempos que se seguem, não haverá sequer tempo para estudar pormenores de execução. Entretanto, nos bastidores, fala-se da "Empresa a criar" mas tudo permanece no limbo.

\section{A nacionalização da eletricidade}

A fusão das empresas entra na agenda governativa mas a conjuntura não dá tempo aos executivos para estudar, planear e projectar. A partir de Setembro de 1974, as mudanças são vertiginosas e as situações de emergência no combate político e ideológico absorvem todas as energias.

Ao nível da sociedade registam-se entretanto movimentações que apontam caminhos alternativos. As tendências centralizadoras e de nacionalização são vistas com desconfiança por parte de alguns quadros técnicos e por parte de sectores do mundo do trabalho. Quanto aos primeiros, a resistência encontra-se sedeada na Companhia Portuguesa de Electricidade - CPE - cujo estatuto de empresa principal de serviço público a torna no centro de gravidade a partir do qual qualquer será construída a futura empresa pública. Ora alguns quadros da CPE temem ver as suas funções, poderes, meios e regalias diluídas pela mistura com serviços menos qualificados tecnologicamente, com pior remuneração e com menores disponibilidades de capital. Em vez da fusão pura e simples, os quadros discutem por isso esquemas organizativos onde exista uma salvaguarda de autonomia em relação à pequena distribuição, por exemplo através da constituição de organizações empresariais separadas com uma Direcção comum. A oposição corporativa à formação de uma empresa única consolida-se num movimento colectivo em 3 de Maio de 1976, altura em que 41 núcleos da Companhia Portuguesa de Electricidade, reunidos na cidade do Porto, aprovam uma moção contra a formação da EDP.

Do lado dos trabalhadores o tema da actualidade é a co-gestão, isto é, a participação de representantes operários nos organismos de direcção das empresas. Trata-se de uma ideia associada às estruturas representativas de trabalhadores que florescem depois da instauração da liberdade de expressão e de associação. Organizadas dentro das empresas públicas mas também nas empresas privadas, estas Comissões Provisórias de Trabalhadores, Conselhos Gerais de Trabalhadores ou Comissões de Trabalhadores, começam por reivindicar aumentos salariais, revisão de condições de trabalho, folgas e dias férias, actualização de pensões de reforma e de assistência médica (ver caixa). Sob o ambiente político revolucionário, rapidamente passam a defender objectivos com maior alcance político-social, nomeadamente o acesso aos órgãos de decisão das empresas. Ora as premissas da co-gestão pelo ênfase que colocam na administração descentralizada, na autonomia local e na partilha do poder executivo apontam para um caminho radicalmente oposto à fusão, concentração, aproveitamento das economias de escala e planeamento centralizado. Quer isto dizer que o debate nacional de partidos, correntes de opinião e forças sociais, sobre as virtudes da propriedade privada ou a superioridade da propriedade pública, se cruza, na escala dos interesses micro sociais, com um outro debate sobre as virtudes e os defeitos da centralização. Deverá existir uma empresa única com sede administrativa em Lisboa, ou devem manter-se empresas locais geridas com autonomia?

As empresas e as reivindicações dos trabalhadores no ano de 1974.

Actas do Conselho de Administração das Companhias Reunidas de Gás e Electricidade.

Verificou-se assim que, além da concessão do aumento geral de vencimentos tinham sido já satisfeitas mais reivindicações, tais como: pagamento de horas suplementares que excedam as 40 horas semanais (trabalho por turnos), revisão dos prémios de condução

\footnotetext{
${ }^{8}$ CD/ME. EDP: Tarifas. Relatório do Grupo de trabalho criado por despacho do Ministro da Administração Interna e do Secretário de Estado da Indústria e Energia de 21 de Junho de 1974, Agosto de 1974.
} 
aos credenciados, revisão dos abonos para refeições e para ajudas de custo e concessão de 30 dias seguidos de ferias para todos os trabalhadores.

Encontram-se ainda em estudo, aguardando solução, outras reivindicações, ou sejam: uniformização das concessões de gás e electricidade, revisão das gratificações de 25 e 40 anos de serviço, pagamento do salário em dias feriados, atribuição de um subsídio para refeições, revisão do esquema geral de vencimentos, remodelação da estrutura da assistência médica, etc.

Foi entretanto solucionada outra reivindicação que se encontrava em estudo, na altura: a melhoria das pensões de reforma e de sobrevivência.

As reivindicações já satisfeitas representam para o exercício corrente um encargo global de cerca de 58.000 contos, sendo 36.000 contos relativos ao aumento geral dos vencimentos e de impostos e de encargos sociais sobre remunerações, 12.000 contos consequência da melhoria das pensões de reforma e de sobrevivência e 10.000 contos o custo das restantes reivindicações. A Comissão Executiva ao tomar as decisões que deram origem a tais encargos tinha tido em consideração os interesses dos trabalhadores e os da empresa no seu conjunto, pelo que pedia ao Conselho a ratificação da orientação seguida. o Conselho deu o seu acordo por unanimidade.

Fontes: CD/ME. CRGE: Livro de Actas do Conselho de Administração das Companhias Reunidas de Gás e Electricidade. Acta nํㅜ 1353. 21 de Agosto de 1974.

Em síntese, verifica-se que a ideia de concentração e de nacionalização veiculada por quadros técnicos e assimilada pelos dirigentes políticos está longe de recolher a unanimidade. As maiores resistências encontram-se significativamente do lado do mundo do trabalho, cujos interesses corporativos podem vir a ser afectados com a formação de uma empresa única.

As vicissitudes do golpe de 11 de Março de 1975, encurtam o debate. Depois do isolamento e da derrota das tropas fiéis ao Presidente da República, António de Spínola, a balança do poder pende para os sectores da esquerda militar que desencadeiam uma contra ofensiva. Reunidas numa Assembleia ad-hoc do Movimento das Forças Armadas, estas forças decidem avançar com um amplo programa de nacionalizações, instituindo um órgão militar permanente de supervisão, o Conselho da Revolução. Entra-se assim numa fase de legitimidade revolucionária em que as circunstâncias ditam as decisões. Embora descontentes com o rumo dos acontecimentos, o Partido Socialista e o Partido Social Democrata, aceitam tacitamente a realidade criada pelas nacionalizações, enquanto o Centro Democrático Social denuncia os perigos da estatização da economia.

Os acontecimentos subsequentes ao decreto de nacionalização da electricidade (Abril de 1975) vêm no entanto mostrar que a reestruturação vai ser muito mais complicada do que o previsto. Desde logo se toma opção cautelosa de não nacionalizar todo o sector, mas somente o núcleo constituído pelas 14 maiores companhias privadas, basicamente sedeadas na distribuição de energia (segunda linha do Quadro 1). Pensa-se também que a fusão numa empresa única pode ser resolvida em três meses, quando vão ser precisos 14 meses para atingir esse objectivo.

Para gerir esta fase de transição é nomeada uma Comissão de Reestruturação do Sector da Electricidade (CRSE) cuja missão consiste em supervisionar, estudar e planear a actividade do sector nacionalizado. Apesar de formalmente concentrada, a hierarquia encontra-se operacional-mente distribuída porque cada uma das empresas mantém a autonomia administrativa e financeira. 0 sector eléctrico entra assim numa fase de equilíbrios instáveis, de negociação, de influências de bastidores e de resistência à plena integração. No dizer de uma testemunha da época, este é o período das "capelinhas" ${ }^{\prime \prime}$, onde cada entidade procura salvaguardar da melhor forma os seus interesses.

Ministros e Secretários de Estado têm um interlocutor privilegiado que é a Comissão de Reestruturação do Sector da Electricidade (CRSE). Descendo um degrau na cadeia de responsabilidades surgem 14

\footnotetext{
${ }^{9}$ Entrevista a Jerónimo da Fonseca. Base de Dados de História oral do projecto: Electricity and the question of energy. Production, distribution and consumption in Portugal. MInidisc JerFo1; JerFo2.Entrevista conduzida por Bruno Cordovil em 21/10/2003.
} 
Comissões Administrativas nomeadas para a gestão corrente de cada uma das empresas nacionalizadas, cujo trabalho é acompanhado por Comissões de Trabalhadores. Finalmente, há todo o tipo de entidades públicas que continuam a apresentar pedidos, propostas, sugestões e reclamações (Câmaras Municipais, Governadores Civis, Grupos de oficiais do exército, Comissões de Planeamento Regional, Comissões de Moradores). Como as várias empresas mantêm a autonomia imbuída em formas de cultura própria, tendem a resistir às tentativas de controle centralizado, agindo em função de interesses locais. Evitam por isso dar todos os dados necessários à entidade central de planeamento, a Comissão de Reestruturação do Sector Eléctrico - CRSE —, de modo a manter uma assimetria de informação que lhes é favorável. Do outro lado da cadeia, o balanço não é famoso: como afirma um dos nomeados da CRSE, [...]

\section{[...] ao longo deste período de existência das Comissões Administrativas, tem-se constatado todo um clima de perniciosidade, de divisão e de desentendimento. Tomam-se linhas de orientação e depois cada empresa, pelas costas, faz o que bem entende ${ }^{10}$.}

A situação é agravada com as quebras na recolha de receita por parte das várias entidades nacionalizadas e pelo recurso a operações de empréstimos de curto prazo para resolver dificuldades de tesouraria e compromissos de investimento. Os "volumes" destes créditos, ao transitarem para os balanços da futura empresa pública a instituir, constituem um argumento para acelerar o processo de fusão.

Inicialmente espera-se que tudo esteja concluído por volta de Julho de 1975. Mas passados os noventa dias previstos para a fundação da nova empresa verifica-se que o caminho ainda está longe do fim. João Cravinho, Ministro da Pasta da Indústria e Tecnologia do IVo Governo Provisório, oriundo do Partido Socialista, renova o mandato da Comissão de Reestruturação do Sector Eléctrico e adia as decisões de fundo por mais uns meses. À equipa inicial, constituída por engenheiros de diferentes proveniências, juntam-se entretanto quatro representantes do mundo do trabalho, saídos da Comissão de Trabalhadores Inter-Empresas.

Por simples despacho ministerial, consolida-se uma cobertura alargada dos vários interesses presentes no sector da electricidade: quadros das empresas nacionalizadas, quadros das empresas públicas, representantes de organismos da administração central, representantes dos trabalhadores. Esta política de cooptação e de integração, traduzida numa espécie de corporativismo sem patrões, contribui para a relativa paz social que existe em pleno verão quente de 1975.

Dos mais variados pontos do país começam entretanto a chegar pressões para "uma reestruturação tendo por base as empresas já com dimensão e integrando nestas outras de menos vulto, os concelhos com distribuição própria - serviços Municipalizados - Federações", ou para uma "uma organização interna de eficácia técnica em zonas tanto quanto possível equilibradas, intercalando adequadamente zonas "ricas" com zonas "pobres"11. Serviços Municipais pedem para entrar no comboio da nacionalização; comissões de trabalhadores recomendam a renovação de mandatos a administradores em funções.

\section{Conclusões: as forças de continuidade}

Na introdução deste texto foi referido que a nacionalização da electricidade não representou uma rutura em relação ao regime ditatorial do Estado Novo. Vimos a este respeito como a ideia de empresa única (1966-1974), de nacionalização técnica (1974-1975) e de nacionalização política (1975-1976) prolongam na prática a estratégia de fusões de empresas de serviço público e de concentração de activos Municipais levadas a cabo durante o consulado de Marcelo Caetano (1968-1974). Mas a noção

\footnotetext{
${ }^{10}$ CD/ME. EDP: Relações Institucionais. Comissão de Reestruturação do Sector da Electricidade, 17 de Julho de 1975, Acta da $12^{\mathrm{a}}$ reunião.

${ }^{11}$ CD/ME. EDP: Relações Institucionais. Comissão de Reestruturação do Sector da Electricidade. 22 de Agosto de 1975, Carta de Vítor Manuel Gonçalves Fernandes engenheiro EHSE para Raul Bessa da CRSE; Sobre Modelos para a Empresa única e integração, de 23 de Maio de 1975.
} 
de continuidade, ao nível das macro políticas seguidas, traduz-se igualmente na continuidade ao nível dos indivíduos. A este respeito, o exame da lista de membros para a Comissão de Reestruturação do Sector Eléctrico - CRSE - revela que não há personagens de segunda escolha, nomeados porque outros saíram do país ou estão indisponíveis. Na verdade, alguns dos quadros de maior destaque nos processos de decisão da engenharia portuguesa, na fase final do Marcelismo, integram a comissão do período revolucionário. Para ilustrar a variedade de percursos é de registar a presença na CRSE dos principais responsáveis nas áreas de estratégia, planeamento de novos centros produtores e de programação financeira da antiga Companhia Portuguesa de Electricidade; de responsáveis pelos estudos para a instalação da central nuclear; de colaboradores do Grémio da Indústria Eléctrica; de figuras de referência das empresas nacionalizadas nomeadamente da União Eléctrica Portuguesa UEP — e das Companhia Reunidas de Gás e Electricidade — CRGE.

Talvez a personalidade mais emblemática na passagem de testemunho do velho para o novo regime, sem sobressaltos de maior, seja Fernando Ivo Gonçalves cuja história de vida acompanha de perto o amadurecimento da indústria em Portugal. Apontado no meio como o delfim e o herdeiro de Ferreira Dias (subsecretário de Estado e Ministro do Estado Novo no período de Oliveira Salazar), Ivo Gonçalves é recomendado ainda jovem para a posição de Director do Repartidor Nacional de Cargas, cargo da maior responsabilidade porque é nessa altura que a coordenação da rede eléctrica entra em funcionamento. A partir daí ocupa posições executivas nas grandes empresas de serviço público (Empresa Termoeléctrica Portuguesa e Companhia Nacional da Electricidade). Quando ocorre o 25 de Abril de 1974, ele é a personalidade no qual os seus pares se revêem. A nomeação para a Comissão de Reestruturação do Sector Eléctrico em pleno período revolucionário garante por isso uma credibilidade acrescida a este organismo. Apesar de formalmente a Comissão ser chefiada por Carlos Pereira Simões, um militar do Movimento das Forças Armadas, na prática todos sabem que a verdadeira liderança está na sombra. Posteriormente, Fernando Ivo Gonçalves surge como a escolha natural para desempenhar as funções de primeiro presidente da empresa EDP.

\section{Referências}

CD/ME. EDP: Relações Institucionais. Relatório do Grupo de trabalho criado pela Comissão nomeada por despacho do Secretário de Estado da Indústria de 23/11/1966 para estudar a reestruturação das empresas concessionárias da rede primária. 23 de Novembro de 1966.

CD/ME. EDP: Relações Institucionais. A reestruturação da electricidade causas e objectivos. Documento de trabalho dactilografado de António Leite Garcia. Julho de 1974.

CD/ME. EDP: Relações Institucionais. Comissão de Reestruturação do Sector da Electricidade, 17 de Julho de 1975, Acta da 12 ${ }^{\mathbf{a}}$ reunião.

CD/ME. EDP: Relações Institucionais. Comissão de Reestruturação do Sector da Electricidade. 22 de Agosto de 1975, Carta de Vítor Manuel Gonçalves Fernandes engenheiro EHSE para Raul Bessa da CRSE; Sobre Modelos para a Empresa única e integração, de 23 de Maio de 1975.

CD/ME. EDP: Tarifas. Relatório do Grupo de trabalho criado por despacho do Ministro da Administração Interna e do Secretário de Estado da Indústria e Energia de 21 de Junho de 1974. Agosto de 1974.

ENTREVISTA a Jerónimo da Fonseca. Base de Dados de História oral do projecto: Electricity and the question of energy. Production, distribution and consumption in Portugal. MInidisc JerFo1; JerFo2. Entrevista conduzida por Bruno Cordovil em 21/10/2003.

VIEGAS, José Manuel. Nacionalizações e Privatizações. Celta: Lisboa, 1996. 